\title{
Numerical analysis of solar updraft power plant integrated with external heat source
}

\author{
Mohammed A. Aurybi ${ }^{1,2}$, Hussain H. Al-Kayiem ${ }^{1, *}$, Syed I. U. Gilani ${ }^{1}$ and Ali A. Ismaee ${ }^{1}$ \\ ${ }^{1}$ Department of Mechanical Engineering, Universiti Teknologi PETRONAS, 32610 Bandar Seri \\ Iskandar, Perak, Malaysia. \\ ${ }^{2}$ Department of Mechanical Engineering, University of Baghdad, Baghdad, Iraq
}

\begin{abstract}
Many countries started to adopt clean energy sources, where solar energy is the first priority. Solar chimney power plant was selected in this study as a system which converts solar thermal energy to electrical power. In this research, hybrid solar chimney power plant model has been proposed as a day and night functional integrated system using external heat source to enhance the system performance and cover the setback of solar absence at night and cloudy days. With the help of ANSYS Fluent software, three-dimensional steady-state of Navier-Stokes and energy equations have been solved. Realized $k-\varepsilon$ two equation turbulent model equations and discrete ordinates (DO) radiation model equations were solved for the conventional model. The results were validated using experimental measurements. Afterward, the influence of thermal enhancing channels installation on the system performance was predicted and analysed in hybrid mode. The simulation results showed that this system could enhance the plant during the day. Percentage of enhancement was $10 \%$ and $14 \%$ for velocity and temperature respectively, and the power output percentage enhancement was $18 \%$ when the solar intensity was $1000 \mathrm{~W} / \mathrm{m}^{2}$, and external heat source mass flow rate and the temperature for each channels was $0.015 \mathrm{Kg} / \mathrm{s}$ and $100^{\circ} \mathrm{C}$ respectively, in comparison with the conventional model.
\end{abstract}

\section{INTRODUCTION}

Solar updraft power plant (SUPP) is considered as a promising technology for utilizing solar energy for power generation. The plant consists of three main components: collector, chimney, and turbine. The collector is circular in shape and composed of a transparent roof which allows the solar radiation to penetrate and then absorbed by the ground. The gap between the collector canopy and the ground allow the air movement underneath it. The chimney is installed in the center of the collector and the turbine is fixed at the chimney base. By the effect of solar radiation through the canopy, heat is absorbed by the ground which in turn heats up the air inside the collector by natural convection then the hot air flow and rise to the chimney by the bouncy effect.

\footnotetext{
* Corresponding author: hussain kayiem@utp.edu.my
} 
The updraft inside the chimney base rotate the turbine and then generate electricity by attached the turbine shaft with a generator. The main constraint of the SCPP is its low efficiency (less than $2 \%$ - total plant efficiency) and the interruption during the night, cloudy and rainy times [1].

Most of the researchers investigated the plant main parts and try to enhance the system. In the same line, [2] proposed a hybrid type of materials as thermal energy storage technique to enhance the SCPP power generation. [3], also proposed hybrid SCPP to enhance the power production at day and cloudy period operation or at night. The model was combined Geothermal/PV/SCPP. On the other side, there are many applied technologies which use and transform the waste energy to useful form. SCPP depending on the solar as the main energy source and some researchers suggested using another source with this system to enhance the performance and to survive the system from power decline at night. Ref. [4] introduced a mathematical model of hybrid SCPP by suggest installing thermal enhancing channels underneath the collector canopy. The proposed channels can be work as a heat exchanger.

[5] and [6] proposed hybrid SCPP model to enhance the plant performance by utilizing metal sheet as the absorber plate underneath the collector instead of the soil, the absorber plate stands as a heat exchanger which extract heat from the hot flue gas that flows through the bottom part of the collector while in the top/front of the absorber plate there was a collector which absorbed the solar energy to warm up the air inside it.

The main challenge of the SCPP is the poor electricity generation at night, so the researchers proposed a new power plant plan by using the SCPP with external heat source.

The main objective of this paper is to introduce a new enhancement technique to improve the performance of SCPP and ensure the continuity of its production for 24 hours a day throughout a week. Furthermore, the aim of this research is to study and analyze numerically the physical properties and heat transfer of air flow inside the collector and chimney to show the enhanced performance of the system with the help of thermal enhancing channels installations.

\section{Proposed model description}

This research presents a hybrid solar chimney power plant as a proposed model, as shown in figure.1. This model would not only increase the efficiency of the power plant during the day, but it would also provide power even when there is no at night time and cloudy days. The technique in this model utilizes the flue gasses or exhausts gasses from a nearby gas turbine power plant or any external waste heat source and converts the waste thermal energy in these exhausts to thermal energy in the SCPP, considering a new form of waste heat energy recapture. Thus, it is an ideal way to reduce global warming. In this way, the thermal energy of the air flow is increased in the solar collector of the plant by using hollow rectangular channels, known as Thermal Enhancing Channels (TECh), situated below the collector cover. The exhaust or flue gases are pushed through the channels by pipe holes and the gases passing through the channels cause heat transfer from walls of the channels to the air flowing below the collector (greenhouse). This phenomenon indicates that the air receives more kinetic energy in addition to that obtained from solar radiation, which in turn increases the temperature of air in an outlet collector, resulting in the enhanced performance of the plant. At the same time, this heat source helps the plant to operate at night. After that, the gases emerging from the channels enter the chimney and increase the updraft air velocity of the exit air flow from the chimney and that called "Cogeneration". 


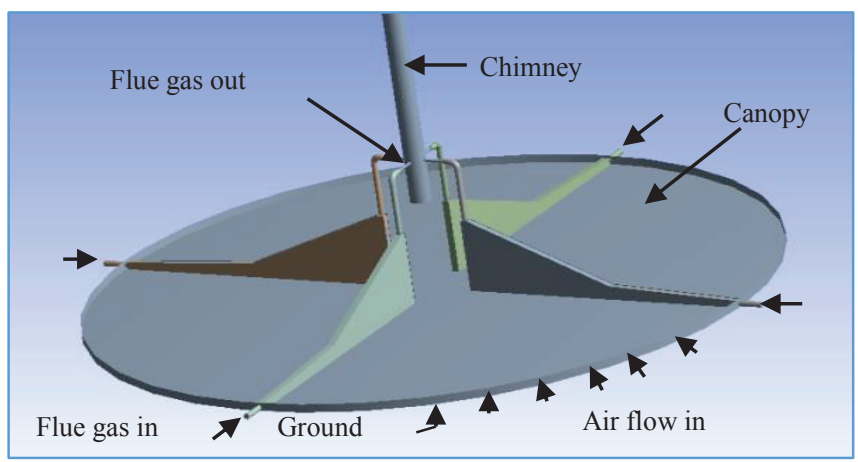

Fig. 1. Schematic diagram of proposed model.

\section{Numerical solution}

The fluid flow inside the model is solved through the conservation equation of mass, momentum, and energy. The governing equations, presented below, have been solved in three dimensions (3D).

Continuity equation:

No change in mass with time is assumed and when the density is constant, the conservation of mass equation can be written as:

$$
\left(\frac{\partial u}{\partial x}+\frac{\partial v}{\partial y}+\frac{\partial w}{\partial z}\right)=0
$$

Conservation of momentum:

The $\mathrm{x}, \mathrm{y}, \mathrm{z}$ components of the momentum equation are determined by equations (2), (3), and (4), respectively:

$$
\begin{aligned}
& \rho \nabla \cdot(u V)=-\frac{\partial p}{\partial x}+\frac{\partial \tau_{x x}}{\partial x}+\frac{\partial \tau_{y x}}{\partial y}+\frac{\partial \tau_{z x}}{\partial z}+S_{x} \\
& \rho \nabla \cdot(v V)=-\frac{\partial p}{\partial y}+\frac{\partial \tau_{x y}}{\partial x}+\frac{\partial \tau_{y y}}{\partial y}+\frac{\partial \tau_{z y}}{\partial z}+S_{y} \\
& \rho \nabla \cdot(w V)=-\frac{\partial p}{\partial z}+\frac{\partial \tau_{x z}}{\partial x}+\frac{\partial \tau_{y z}}{\partial y}+\frac{\partial \tau_{z z}}{\partial z}+S_{z}
\end{aligned}
$$

The source terms $S_{x}, S_{y}$, and $S_{z}$ in (2), (3) and (4) represent the body force.

In equations $(2,3$, and 4$)$ the Boussinesq model is used by setting up the problem with fluid density as a function of temperature. This model treats density as a constant value in all solved equations, except for the buoyancy term in the momentum equation:

Equation (5) is valid when $(1-\beta \Delta T) \ll 1$

$$
(\rho)=\rho_{\circ}(1-\beta \Delta T)
$$

Conservation of energy:

The general flow equation after considered a constant thermal conductivity and specific heat of fluid elements as follows:

$$
\rho C_{p}\left(\frac{\partial(u T)}{\partial x}+\frac{\partial(v T)}{\partial y}+\frac{\partial(w T)}{\partial z}\right)=k\left(\frac{\partial^{2} T}{\partial x^{2}}+\frac{\partial^{2} T}{\partial y^{2}}+\frac{\partial^{2} T}{\partial z^{2}}\right)+S_{E}
$$




\subsection{Turbulence and radiation models}

Realized $k-\varepsilon$ two equation turbulent model which considered one of the most widely used turbulent models is used in the numerical simulation. In this model the turbulent kinetic energy and dissipation rate can be computed as follows:

$$
\begin{aligned}
& \rho \nabla \cdot[\bar{v} k]=\nabla \cdot\left[\mu_{e f f, k} \nabla k\right]+S_{k} \\
& \rho \nabla \cdot[\bar{v} \varepsilon]=\nabla \cdot\left[\mu_{e f f, \varepsilon} \nabla \varepsilon\right]+S_{\varepsilon}
\end{aligned}
$$

Where:

$S_{k}$ and $S_{\varepsilon}$ are the kinetic energy and dissipation rate source term.

The enhanced wall treatment $\varepsilon$-Equation is used in numerical solution as recommended by many literatures [10] to solve the near wall problem. Discrete Ordinates (DO) Radiation Model is used to solve the radiation problem. The DO model considers the radiation transfer equation for scattering, emitting and absorbing media at position $r \overrightarrow{\text { in }}$ the direction $\mathrm{s} \rightarrow$ after using the gray-band model and modeling the non-gray radiations as follows:

$$
\nabla \cdot\left(I_{\lambda}(\vec{r}, \vec{s}) \vec{s}\right)+\left(\alpha_{\lambda}+\sigma_{s}\right) I_{\lambda}(\vec{r}, \vec{s})=\alpha_{\lambda} n^{2} I_{b \lambda}+\frac{\sigma_{s}}{4 \pi} \int_{0}^{4 \pi} I_{\lambda}(\vec{r}, \vec{s}) \phi(\vec{s}, \vec{s}) d \hat{\Omega}
$$

$\vec{r}=$ position vector, $\vec{s}=$ direction vector, $\vec{s}=$ scattering direction vector, $\alpha=$ absorption coefficient, $n=$ refractive index, $\sigma_{s}=$ scattering coefficient, $\sigma=$ Stefan-Boltzmann constant $\left(5.669 \times 10^{-8} \mathrm{~W} / \mathrm{m}^{2} \cdot \mathrm{K}^{4}\right), \quad I=$ radiation intensity, which depends on $\vec{r} \operatorname{and} \vec{s}, T=$ temperature, $\phi=$ face function, $\Lambda^{\prime}=$ solid angle.

$\lambda=$ wave length, $\alpha_{\lambda}=$ spectral absorption coefficient, $I_{b \lambda}=$ black body intensity.

\section{Boundary conditions and dimensions}

First, the Eqns. (1) - (9) were solved numerically with conventional model geometry which was implemented in the solar research site (SRS) at University Technology PETRONAS, as shown in figure 2. The dimensions of the model are given in Table 1 and the boundary conditions are presented in Table 2 . The value of solar radiation adopted in the simulation was $1000 \mathrm{~W} / \mathrm{m}^{2}$ and ambient temperature was $307 \mathrm{~K}$.

Table 1. Dimensions of the conventional model.

\begin{tabular}{|l|c|}
\hline Parameter & Dimension(m) \\
\hline Collector radius & 6 \\
\hline Collector height at inlet & 0.05 \\
\hline Collector height at outlet & 0.65 \\
\hline Chimney height & 6.5 \\
\hline Chimney Diameter & 0.15 \\
\hline
\end{tabular}

Table 2. Boundary conditions for conventional model

\begin{tabular}{|l|c|c|}
\hline Zone & Type & Value \\
\hline Ground & Interface wall & Interface \\
\hline Canopy & Semi-transparent wall & $h=8 \mathrm{w} / \mathrm{m}^{2} T_{a m b}=307 \mathrm{k}$ \\
\hline Chimney & wall & Adiabatic \\
\hline Collector inlet & Pressure inlet & $\Delta P=0, T_{a m b}=307 \mathrm{k}$ \\
\hline Chimney outlet & Pressure outlet & $\Delta P=0, T_{a m b}=307 \mathrm{k}$ \\
\hline
\end{tabular}




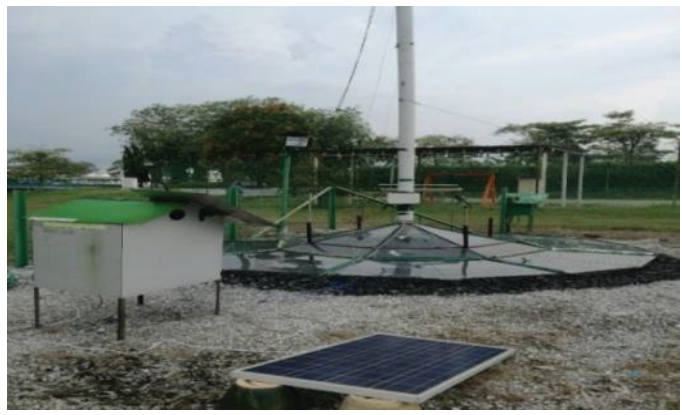

Fig. 2. Implemented solar chimney conventional model.

Physical properties of the materials employed in the simulation are given in Table 3. A 3-D and steady state incompressible flow with second-order upwind discretization and pressure-based coupled algorithm were used as a solver in CFD simulation.

Table 3. Properties of materials used in the simulation

\begin{tabular}{|l|c|c|c|}
\hline Physical property & Perspex & $\begin{array}{c}\text { Ground } \\
\text { (black pebble) }\end{array}$ & $\begin{array}{c}\text { Chimney } \\
\text { (PVC) }\end{array}$ \\
\hline Absorption coefficient & 0.06 & 0.9 & 0.04 \\
\hline Transmission coefficient & 0.92 & 0 & 0 \\
\hline Density $\rho\left(\mathrm{kg} / \mathrm{m}^{3}\right)$ & 2700 & 2640 & 833 \\
\hline Specific heat $(\mathrm{J} / \mathrm{kg} . \mathrm{K})$ & 840 & 820 & 1170 \\
\hline Thermal conductivity $(\mathrm{W} / \mathrm{m} . \mathrm{K})$ & 0.78 & 1.73 & 0.19 \\
\hline Emissivity & 0.9 & 0.9 & 0.91 \\
\hline
\end{tabular}

\subsection{Grid independence}

It is logic to use fine mesh with a minimum mesh sizing to give a more accurate solution, but that means more computer cost and time. Grid independence is achieved by starting with coarse mesh which was defaults selection by mesh generation code, then medium and fine mesh. After that more reduction in grid size was conducted until the no change in output parameters is done. The structured mesh tetrahedral type was used to achieve the mesh generation for conventional SCPP model and mesh sizing (Maximum size $0.03 \mathrm{~m}$ and minimum size $0.001 \mathrm{~m}$ ) were used to get the solution for the conventional model with percentage error $5 \%$ for the velocity at the chimney base comparing with the experimental value, and same mesh size with unstructured mesh hexahedral type were used for proposed model after mesh independence test as shown in figure. 3 .

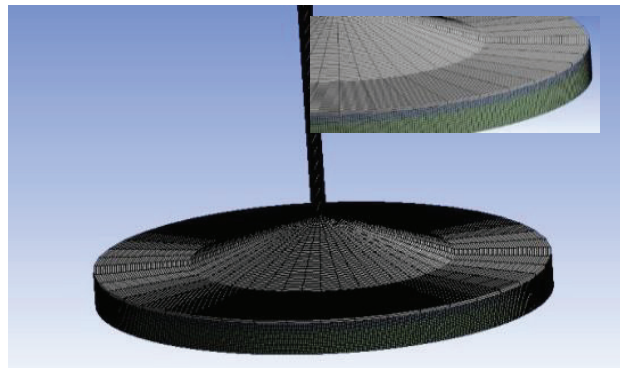

(a) Structured mesh tetrahedral type.

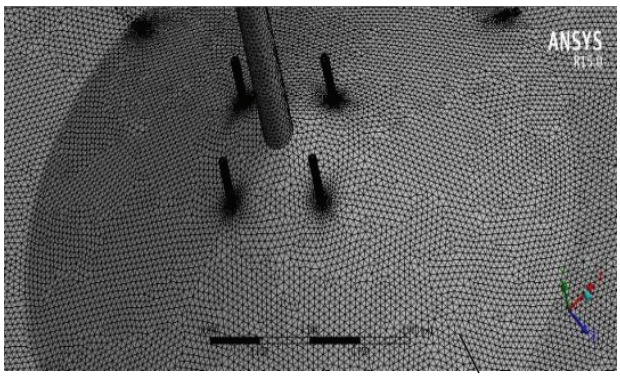

(b) Unstructured mesh hexahedral type.

Fig. 3. Structure and unstructured mesh generation for the conventional and proposed model. 


\section{Result and discussion}

Velocity and temperature contour maps were considered based on simulation results with no load condition and solar intensity of $1000 \mathrm{~W} / \mathrm{m}^{2}$. It could be observed that by simulation, the maximum velocity was observed at the chimney base and the temperature distributions increased when the solar insolation increased and this due to the solar intensity raised the temperature of storage media (pebble) inside the collector. Maximum temperature and velocity in simulation for the conventional model were in good agreement with the experimental readings depicting logical and reasonable error ratio. The maximum velocity for the numerical solution of the convenience model was $1.97 \mathrm{~m} / \mathrm{s}$ and the temperature was $325 \mathrm{~K}\left(\Delta \mathrm{T}=18^{\circ} \mathrm{C}\right)$ as shown in figure. 4 . Same boundary conditions are given in Table 2 with the addition of channels at hybrid mode with the external heat source is provided at this stage.

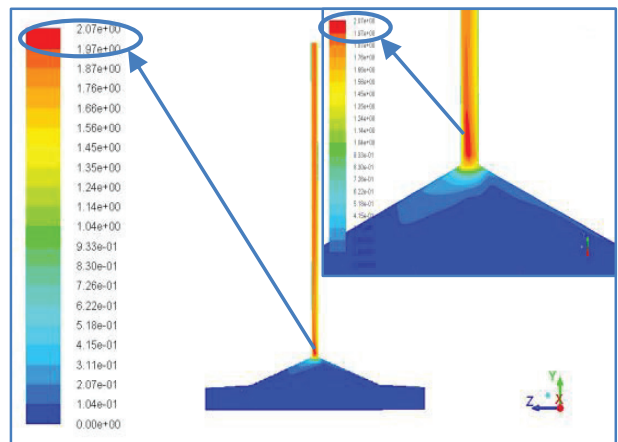

(a) Velocity contour distribution.

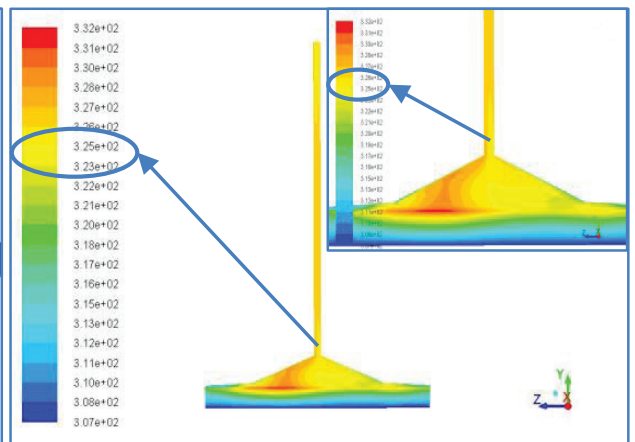

(b) Temperature contour distribution.

Fig. 4. Velocity and temperature distribution for the conventional model.

Figure 5 illustrates the temperature and velocity distribution for the proposed model. The results showed that the percentage of enhancement of velocity and temperature for the working fluid of the model after adding channels and pushed flue gas with $0.015 \mathrm{~kg} / \mathrm{s}$ and $100^{\circ} \mathrm{C}$ for mass flow rate and temperature inside each channel were $10 \%(\mathrm{v}=2.2 \mathrm{~m} / \mathrm{s})$ and $14 \%\left(\mathrm{~T}=327 \mathrm{~K}, \Delta \mathrm{T}=20^{\circ} \mathrm{C}\right)$ respectively, with no load as compared with no channels case. The performance of the plant (collector efficiency and output power) was calculated according to Schlaich [9]. Table 4 shows the enhancement of the proposed model to the conventional one for velocity, temperature, and performance.

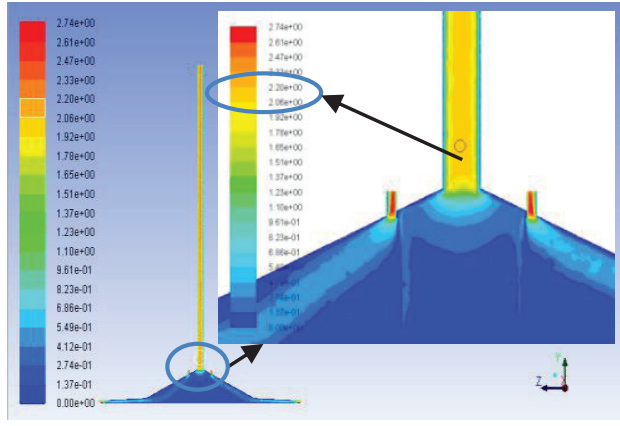

(a) Velocity contour distribution.

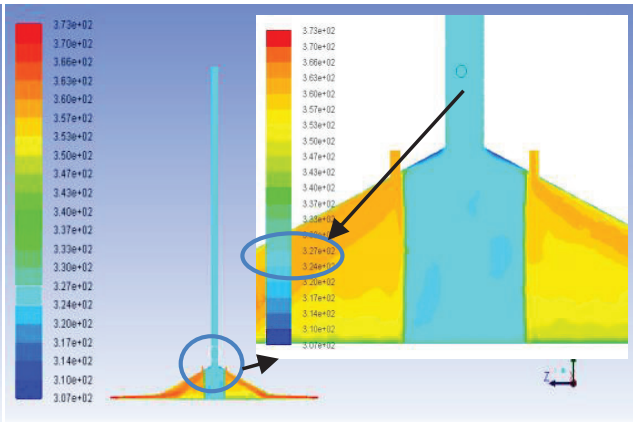

(b) Temperature contour distribution.

Fig. 5. Velocity and temperature distribution for the proposed model. 
Table 4. Experimental readings and simulation results

\begin{tabular}{|l|c|c|c|c|}
\hline \multicolumn{1}{|c|}{ Model } & $\begin{array}{c}\text { Max. } \\
\text { Velocity } \\
\mathbf{( m / s )}\end{array}$ & $\begin{array}{c}\text { Temp. } \\
\text { Diff } \\
\Delta \mathbf{T}(\mathbf{K})\end{array}$ & $\begin{array}{c}\text { Collector } \\
\text { thermal } \\
\text { efficiency } \\
\mathbf{( \% )}\end{array}$ & $\begin{array}{c}\text { Power } \\
\text { output } \\
\mathbf{( W )}\end{array}$ \\
\hline Conventional model (experimental) & 1.89 & 17.6 & 3.7 & 0.07 \\
\hline Conventional model (simulation) & 1.97 & 18 & 3.9 & 0.073 \\
\hline Proposed model with external heat source & 2.2 & 20 & 4.8 & 0.09 \\
\hline Percentage of enhancement & $10 \%$ & $14 \%$ & $18.8 \%$ & $18 \%$ \\
\hline
\end{tabular}

\section{Conclusions}

The simulation results of the conventional model showed a good agreement with the experimental results which confirm the accuracy of the simulation procedure. The numerical results disclose that the proposed technique has a momentous impact on the aerothermal and performance characteristics. The velocity and temperature enhancements were $10 \%$ and $14 \%$, respectively, and the power output percentage enhancement was $18 \%$. Also, it can be concluded that there is a possibility to use the proposed model relying on solar energy (solar mode during the day) or an external heat source (during the night) or both (hybrid during the day) to produce electricity.

The logistic, technical and financial assistance provided by Universiti Teknologi PETRONAS is greatly acknowledged. In particular, the main author acknowledges Ministry of Industry and Minerals - Iraq (SIER-Company) for assistance to pursue his doctorate.

\section{References}

1. H. H. Al-Kayiem. WIT Transactions on Ecology and the Environment, Vol 179, (C) WIT Press. (2013)

2. A. A. Ismaeel, H. H. Al-Kayiem, A. T. Baheta and M. A. Aurybi. International Energy Journal 16, 11-24. (2016)

3. H. Alrobaei, Higher Institute of Engineering, P.O. Box: 61297; HOON; Libya. (2007)

4. M. A. Aurybi, H. H. Al-Kayiem, S. I. U. Gilani and A. A. Ismaeel. ARPN Journal of Engineering and Applied Sciences. 11, 20, (2016).

5. H. H. Al-Kayiem, K. Y. Yin and C. Y. Sing. WIT Transactions on Engineering Sciences, 7, (C) WIT Press. (2012)

6. A. O. Chikere, H. H. Al-Kayiem, and Z. A. Abdul Karim. Conference paper, 978-14577-1884-7/11/2011 IEEE. (2011)

7. J. Schlaich, and C. Maurer, Geislingen, Germany. (1995)

8. $\quad$ ANSYS Fluent Theory Guide. (2013) 